\title{
Intact Enhancement of Declarative Memory for Emotional Material in Amnesia
}

\author{
Stephan B. Hamann, ${ }^{1}$ Larry Cahill, ${ }^{3}$ James L. McGaugh, ${ }^{3}$ and
}

Larry R. Squire ${ }^{1,2,4}$

Departments of ${ }^{1}$ Psychiatry and ${ }^{2}$ Neurosciences

University of California

La Jolla, California 92161

${ }^{3}$ Center for the Neurobiology of Learning and Memory

and Department of Psychobiology

University of California

Irvine, California 92697-3800

\begin{abstract}
Emotional arousal has been demonstrated to enhance declarative memory (conscious recollection) in humans in both naturalistic and experimental studies. Here, we examined this effect in amnesia. Amnesic patients and controls viewed a slide presentation while listening to an accompanying emotionally arousing story. In both groups, recognition memory was enhanced for the emotionally arousing story elements. The magnitude of the enhancement was proportional for both amnesic patients and controls. Emotional reactions to the story were also equivalent. The results suggest that the enhancement of declarative memory associated with emotional arousal is intact in amnesia. Together with findings from patients with bilateral amygdala lesions, the results indicate that the amygdala is responsible for the enhancement effect.
\end{abstract}

\section{Introduction}

Several studies with humans and experimental animals have indicated that emotionally arousing material is often more memorable than neutral material. In nonhuman animals, the mechanism for this effect has been linked to the interaction of peripheral adrenergic systems with cholinergic,

${ }^{4}$ Corresponding author. Present address: Veterans Affairs Medical Center (V-116A), La Jolla, California 92161. opioid peptidergic, and GABAergic systems in the amygdala (McGaugh et al. 1993). A recent study of human memory has also implicated $\beta$-adrenergic mechanisms (Cahill et al. 1994) in the enhancing effect of emotional arousal. Volunteers who viewed an illustrated, emotionally arousing story exhibited better long-term memory for the emotional content of the story than the neutral content. However, this enhancement was blocked by propranolol, a $\beta$-adrenergic antagonist. Recent findings from two patients with bilateral lesions apparently restricted to the amygdala have suggested additionally that the amygdala critically mediates the enhancing effect of emotional arousal on declarative memory (Cahill et al. 1995; Adolphs et al., this issue).

Little is known about the effect of lesions to other medial temporal lobe (nonamygdala) and midline diencephalic brain structures on memory for emotionally arousing material. That is, although it is well established that such lesions impair declarative memory, it is unclear whether this impairment is equivalent for both neutral and emotionally arousing material. In addition, it is unclear whether the emotional reactions of amnesic patients are normal.

Most clinical and experimental reports of emotional reactions in amnesic patients have focused on patients with alcoholic Korsakoff's syndrome (Rapaport 1961; Talland 1967). These early studies described the emotional responses of such patients as abnormal. Later studies have found these patients to be sometimes less reactive to emotional stimuli than controls (Markowitsch et al. 1986), sometimes more reactive than controls (Oscar-Berman et al. 1990), and sometimes normally reactive

LEARNING \& MEMORY 4:301-309 @ 1997 by Cold Spring Harbor Laboratory Press ISSN1072-0502/97 \$5.00

$$
\begin{array}{lllllllllllllll}
\hline & E & A & R & N & I & N & G & \begin{array}{c}
\boldsymbol{X} \\
301
\end{array} & M & E & M & O & R & Y
\end{array}
$$


(Douglas and Wilkenson 1993). The use of different measures and materials to assess reactivity complicates the interpretation of the results.

A few studies have examined emotional memory in amnesic patients with Korsakoff's syndrome (Davidoff et al. 1984; Markowitsch et al. 1984; Granholm et al. 1985). Although these studies suggest that patients with Korsakoff's syndrome can exhibit enhanced declarative memory for some types of emotionally arousing material, it is difficult to draw definite conclusions from these studies because of anomalous and inconsistent results (e.g., an emotional enhancement effect on memory in patients with Korsakoff's syndrome but no such effect in control subjects), insufficient information regarding whether emotional reactions were normal in the patients with Korsakoff's syndrome, and the use of different materials across studies. In addition, none of these studies examined the critical issue of whether the emotional enhancement effect is of proportional magnitude in amnesic patients and control subjects.

To our knowledge, only one study has concurrently assessed both emotional reactions and emotional memory in amnesic patients. In that study emotional reactions and memory for a wide range of visual, emotionally arousing color photographs (both pleasant and unpleasant) were assessed in amnesic patients with Korsakoff's syndrome and amnesic patients with other etiologies (Hamann et al. 1997). Emotional reactions were intact in the amnesic patients. Although memory was impaired overall in the patients, memory for emotionally arousing stimuli was enhanced, and the enhancement was proportional in amnesic patients and control subjects.

The objective of the current study was to examine whether the enhancing effects of an emotionally arousing narrative on memory would also occur in amnesic patients with medial temporal lobe or diencephalic lesions. Our purpose was twofold. First, we attemped to determine whether the results obtained previously by some of us (Hamann et al. 1997) would generalize to a more ecologically natural paradigm (involving a connected series of pictured events rather than a randomly ordered series of photographs). In addition, because the emotional story paradigm used in the current study has been shown to be sensitive to amygdala damage in humans (Cahill et al. 1995; Adolphs et al., this issue), our aim was to obtain directly comparable data from amnesic patients by using this same paradigm. A normal effect of emo- tional arousal on memory in amnesia would be consistent with the view that the brain structures responsible for the effect of emotional arousal on memory (e.g., the amgydala) are distinct from the medial temporal lobe structures critical for declarative memory (Squire and Zola-Morgan 1991).

We used the same illustrated story paradigm previously demonstrated to be emotionally arousing and also to enhance declarative memory (Heuer and Reisberg 1990; Cahill et al. 1994; Cahill and McGaugh 1995; Adolphs et al., this issue). In this paradigm, subjects view a slide show, accompanied by a story narrative, which tells of a boy who is hit by a car and rushed to the hospital for surgery. Emotional arousal and declarative memory increased for the central portion of the story (which deals with the accident and surgery) compared with the initial and final portions of the story (which deal with relatively neutral events) (for the complete verbatim narrative, see Adolphs et al., this issue, experiment 2). Importantly, this emotion-associated memory enhancement has been found to be absent in two patients with bilateral lesions of the amygdala (Cahill et al. 1995; Adolphs et al., this issue).

To examine whether the effect of emotional arousal on memory is normal or abnormal in amnesia, we presented the illustrated, narrated story to a group of nine amnesic patients of differing etiologies (see Tables 1 and 2) and two groups of age- and education-matched control subjects. Immediately following the story presentation, the subjects rated the strength of their emotional responses to the story. Declarative memory for elements of the story presentation was subsequently assessed with a multiple-choice recognition test. The amnesic patients (AMN, $\boldsymbol{n}=9$ ) and one group of control subjects (CON, $n=9$ ) were tested at a short delay ( $2 \mathrm{~min}$ ). Because the effect of emotional arousal on memory might differ depending simply on whether the overall level of memory was high or low (e.g., in the control and the amnesic groups, respectively), a second group of control subjects (CON-DELAY, $n=12$ ) was tested one week after presentation of the story.

\section{Materials and Methods}

\section{AMNESIC PATIENTS}

Nine amnesic patients (six men and three women) participated in this study. Four had Korsakoff's syndrome (three men and one woman). All

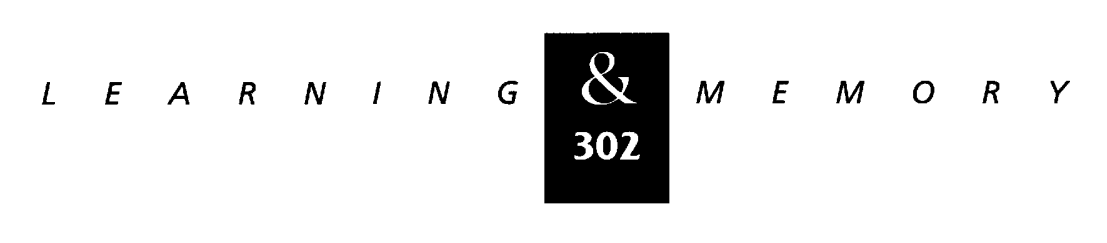


Table 1: Characteristics of amnesic patients

\begin{tabular}{lcccccccc}
\hline & & & & \multicolumn{5}{c}{ WMS-R } \\
\cline { 5 - 9 } Patient & $\begin{array}{c}\text { Age } \\
\text { (years) }\end{array}$ & Lesion & $\begin{array}{c}\text { WAIS-R } \\
\text { IQ }\end{array}$ & attention & verbal & visual & general & delay \\
\hline N.A. & 58 & Dien & 109 & 102 & 67 & 89 & 68 & 71 \\
R.C & 80 & Dien & 106 & 115 & 76 & 97 & 80 & 72 \\
N.F. & 60 & Dien & 94 & 91 & 62 & 73 & 53 & $<50$ \\
P.N. & 69 & Dien & 99 & 81 & 77 & 73 & 67 & 53 \\
J.W. & 60 & Dien & 98 & 104 & 65 & 70 & 57 & 57 \\
A.B. & 59 & HF & 104 & 87 & 62 & 72 & 54 & $<50$ \\
P.H. & 74 & HF & 120 & 117 & 67 & 83 & 70 & 57 \\
L.J. & 59 & HF & 98 & 105 & 83 & 60 & 69 & $<50$ \\
M.H. & 76 & Unk & 107 & 104 & 83 & 83 & 78 & 80 \\
Mean & 66 & & 103.9 & 100.7 & 71.3 & 77.8 & 66.2 & 60.0 \\
\hline
\end{tabular}

Note: The WAIS-R and the WMS-R indexes yield a mean score of 100 in the normal population, with a standard deviation of 15. The WMS-R does not provide scores for those who score below 50. Therefore, the three scores below 50 were scored as 50 for calculating a group mean. (WAIS-R) Wechsler Adult Intelligence Scale--Revised; (WMS-R) Wechsler Memory Scale-Revised; (Dien) diencephalon; (HF) hippocampal formation; (Unk) unknown.

of them had participated in quantitative magnetic resonance imaging (MRI) studies, which demonstrated reductions in the volume of the mammillary nuclei (for R.C., J.W., and P.N., Squire et al. 1990; for N.F., L.R. Squire, unpubl.).

Five other amnesic patients were also tested (three men and two women). Two of these patients had bilateral reduction in the size of the hippocampal formation confirmed by MRI (for P.H., Squire et al. 1990; for LJ., L.R. Squire, unpubl.). Patient P.H. had a 6-year history of 1- to 2-min attacks (of possible epileptic origin) in association

Table 2: Memory test performance of amnesic patients

\begin{tabular}{|c|c|c|c|c|c|c|c|c|}
\hline \multirow[b]{2}{*}{ Patient } & \multirow{2}{*}{$\begin{array}{c}\text { Diagram } \\
\text { recall }\end{array}$} & \multicolumn{3}{|c|}{ Paired associates } & \multirow{2}{*}{$\begin{array}{c}\text { Percent } \\
\text { word } \\
\text { recall }\end{array}$} & \multirow{2}{*}{$\begin{array}{l}\text { Percent } \\
\text { word } \\
\text { recognition }\end{array}$} & \multirow{2}{*}{$\begin{array}{c}50 \\
\text { words }\end{array}$} & \multirow{2}{*}{$\begin{array}{c}50 \\
\text { faces }\end{array}$} \\
\hline & & trial 1 & trial 2 & trial 3 & & & & \\
\hline N.A. & 17 & 0 & 0 & 2 & 49 & 93 & 34 & 42 \\
\hline R.C & 3 & 0 & 0 & 3 & 19 & 85 & 37 & 30 \\
\hline N.F. & 4 & 0 & 0 & 2 & 36 & 76 & 28 & 27 \\
\hline P.N. & 2 & 1 & 1 & 1 & 29 & 83 & 31 & 31 \\
\hline J.W. & 4 & 0 & 0 & 2 & 28 & 96 & 29 & 34 \\
\hline A.B. & 4 & 1 & 1 & 1 & 33 & 83 & 32 & 33 \\
\hline P.H. & 3 & 0 & 0 & 1 & 27 & 84 & 36 & 34 \\
\hline L.J. & 3 & 0 & 0 & 0 & 40 & 93 & 33 & 29 \\
\hline M.H. & 2 & 0 & 4 & 2 & 41 & 91 & 27 & 36 \\
\hline Mean & 4.7 & 0.2 & 0.7 & 1.6 & 33.6 & 87.1 & 31.9 & 32.9 \\
\hline Control $(n=8)$ & 20.6 & 6.0 & 7.6 & 8.9 & 71 & 98 & 41.1 & 38.1 \\
\hline
\end{tabular}

Note: The diagram recall score is based on delayed $(12 \mathrm{~min}$ ) reproduction of the Rey-Osterrieth figure (Osterrieth 1944; maximum score $=36$ ). The average score for copying the figure was 29.1, a normal score (Kritchevsky et al. 1988). The paired associate scores are the number of word pairs recalled on three successive trials (maximum score $=10$ per trial). The word recall score is the percentage of words identified correctly on five successive study-test trials (Rey 1964). The word recognition score is the percentage of words identified correctly by yes-no recognition across five successive study-test trials. The score for words and faces is based on a 24-hour recognition test of 50 words or 50 faces (modified from Warrington 1984; maximum score $=50$, chance $=25$ ). Patient N.A. is not severely impaired on the nonverbal memory tests because his brain injury is primarily left unilateral. The mean scores for healthy control subjects shown for these tests are from Squire and Shimamura (1986).

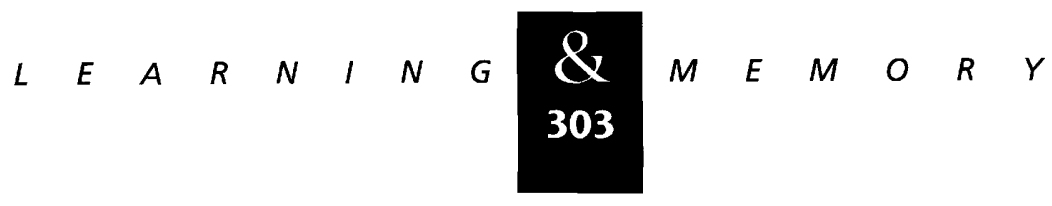


with gastric symptoms and transient memory impairment. In 1989 he suffered a series of small attacks that resulted in marked and persisting memory impairment. Patient L.J. became amnesic gradually during 1988 and 1989 without any known precipitating event. Her memory impairment has remained stable since that time. Patient A.B. was unable to participate in MRI studies, but the etiology of his amnesia (anoxia) is consistent with hippocampal damage. Patient M.H. experienced a sudden onset of severe memory problems thought to be attributable to cerebral ischemia. The locus of her damage is unknown. Finally, patient N.A. became amnesic, primarily for verbal material, following a stab wound to the left diencephalic region with a miniature fencing foil (Teuber et al. 1968; Squire et al. 1989).

As illustrated in Tables 1 and 2, these patients have amnesia of moderate severity. The mean age of the patients was 66 years at the beginning of the study, and they had an average of 13.3 years of education. Immediate and delayed (12-min) recall of a short prose passage averaged 5.0 and 0 segments, respectively (Gilbert et al. 1968; maximum number of segments $=21$ ). The mean score on the Dementia Rating Scale was 132.8 (Mattis 1976; maximum score $=144$ ), with most points being lost from the Memory subscale (mean points lost $=6.1$ ). The mean score for the Boston Naming Test was 56.3 (Kaplan et al. 1983; maximum score $=60$ ).

\section{CONTROL GROUPS}

The control $(n=9)$ and control-delay $(n=12)$ groups were employees or volunteers at the San Diego Veteran's Affairs Medical Center or were recruited from the retirement community of the University of California, San Diego. The control group consisted of four men and five women selected to match the amnesic patients with respect to the mean and range of their ages, years of education, and scores on the Information and Vocabulary subtests of the Wechsler Adult Intelligence Scale (WAIS-R; Wechsler 1981). They averaged 66 years of age (range $=59-76$ ), 14.4 years of education, and 21.0 and 55.7 on the Information and Vocabulary subtests, respectively (amnesic patients $=19.2$ and 54.2, respectively). Immediate and delayed recall of the short prose passage averaged 7.4 and 6.6 segments, respectively.

An additional control group (control-delay) was tested after a longer delay ( 1 week) than the first control group to bring their level of memory performance into the range of the amnesic patients. This group consisted of three men and nine women selected in the same way as the first control group (above). They averaged 64 years of age $($ range $=46-76), 15.1$ years of education, and 21.8 and $\mathbf{5 5 . 8}$ on the Information and Vocabulary subtests, respectively. Immediate and delayed recall of the short prose passage averaged 7.0 and 6.0 segments, respectively.

\section{PROCEDURE}

The pictorial slides used in the current study were the same 11 slides used in experiment 2 of Adolphs et al. (this issue). This set of slides is also identical to the one used in Cahill et al. (1994), except that the current set omits one slide that was poorly remembered by virtually all subjects (a pseudocolored brain image).

In the study phase, all subjects viewed the same illustrated story, consisting of 11 slides, and one sentence of narration on audio tape for each slide. The slides were presented on the screen of a Kodak Caramate slide viewer at a rate of 1 slide/10 sec. Subjects were instructed to watch the illustrated story carefully in the same way that they might watch an interesting television program. The first phase of the story (nonemotional) depicted a mother taking her young son to visit his father at work (slides 1-4). In the second phase (emotional), the boy was badly hurt in an automobile accident and surgeons struggled to save the boy's life (slides 5-8). The final phase (nonemotional) depicted the mother leaving the hospital (slides 9-11).

Immediately after the end of the slide presentation, all subjects were asked to rate on a scale of 0-10 (with 0 indicating "not emotional" and 10 indicating "highly emotional") how emotional they personally found the story to be by marking the scale at the appropriate point. Following this rating phase and, on average, $-2 \mathrm{~min}$ after the end of the slide show, amnesic patients and control subjects were given a 76-item multiple-choice recognition test. For each question, one correct and three plausible alternative answers were listed (chance performance $=25 \%$ ). The questions related to both the visual and narrative aspects of each slide (5-9 questions per slide).

The recognition questions were arranged in

$$
\text { ……‥ }
$$


three groups, according to whether they referred to the first (29 questions), second (28 questions), or final phase of the story (19 questions). The order in which memory for the three story phases was assessed was counterbalanced across subjects. A brief one-sentence description was provided before the testing of each story phase to orient subjects to which phase of the story was being assessed. Within each group of recognition questions, the individual test items assessed memory for each slide in the same order that the slides had been presented (e.g., for phase 1, slides 1, 2, 3, and then 4).

\section{Results}

Emotional ratings of the story were equivalent for the amnesic patients and the two groups of control subjects, $F(2,29)=1.18, \quad \mathrm{MS}_{\mathrm{e}}=4.01$, $P>0.32$. Mean emotional ratings on the $1-10$ response scale $=7.6 \pm .7,7.6 \pm 0.5$, and $6.5 \pm 0.6$ for the AMN, CON, and CON-DELAY groups, respectively (here and elsewhere, numbers following the \pm sign indicate the s.E.M.). Figure 1 shows the mean percentage correct recognition scores as a function of story phase for the CON, CON-DELAY, and AMN groups. As expected, the amnesic patients remembered each phase of the story more poorly than the CON group: $t \mathrm{~s}(16)>3.50, P \mathrm{~s}<0.01$ for the three story phases. Recognition was better for phase 2 of the story than for phase 1 of the story in

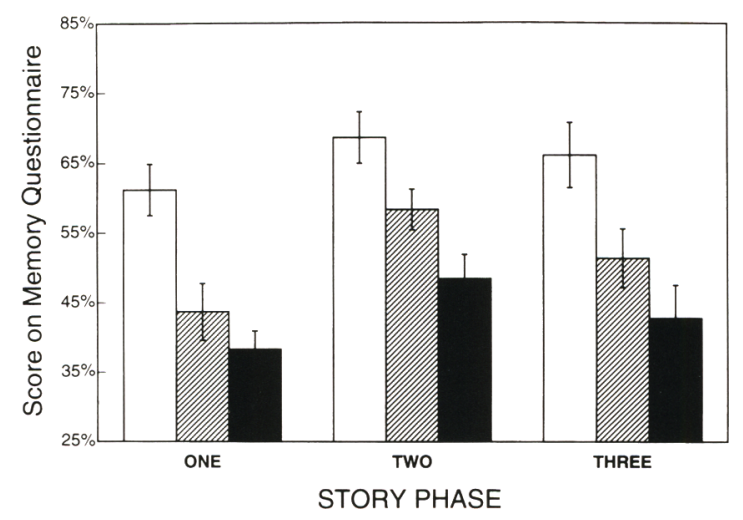

Figure 1: Recognition scores (percent correct) on the memory questionnatire for the CON (open bar) $(n=9)$, CON-DELAY (shaded bar) $(n=12)$, and AMN (solid bar) $(n=9)$ groups as a function of story phase. The second phase of the story contained more emotional content than the other two phases. Error bars indicate S.E.M. Chance performance $=25 \%$. both the AMN and CON groups, although this difference fell short of significance in the CON group (AMN: $t(8)=3.80, P<0.01 ; \quad \operatorname{CON} ; t(8)=2.09$, $P<0.07)$. There were no other significant differences between story phases for either group: all $t$ s $<1.09, P>0.31$. Recognition memory performance did not differ depending on the order in which the three phases of the story were tested (across all subjects, $F(2,29)<1$ ).

The AMN group was then compared with the CON-DELAY group to determine whether the enhancement of recognition memory associated with emotion was proportional for amnesic patients and control subjects when the level of performance for control subjects was brought into range of the scores obtained by the amnesic patients. The introduction of a longer study-to-test delay interval (1 week) for the CON-DELAY group was successful in bringing the overall recognition performance in this group to a level close to (albeit still slightly above) the level in the AMN group in the first story phase. Recognition memory for the CON-DELAY and AMN groups was similar for the first and third phases of the story: $t(19)=1.02, P>0.32$ and $t(19)=1.35, P>0.19$. In addition, memory for phase 2 of the story (the emotionally arousing phase) was improved in both groups to a similar extent, as indicated by the lack of a Group (CONDELAY vs. AMN) $\times$ Phase (1 vs. 2) interaction, $F(1,19)<1$. Despite the lack of a Group $\times$ Phase interaction, recognition performance was higher in the CON-DELAY group than in the AMN group for emotional phase 2: $58.3 \%$ versus $48.4 \%$, $t(19)=2.19, P=0.04$.

To explore this aspect of the data further, we more closely matched the AMN and CON-DELAY groups on memory performance for phase 1 by excluding from analysis three amnesic patients who had scored very poorly on phase 1 (P.H., 27.6\%; P.N., 27.6\%; A.B., 34.5\%). The remaining group of six amnesic patients [AMN(6)] scored $42.5 \%$ correct on phase 1 and $53.6 \%$ correct on phase 2 of the story $[t(5)=3.41, P<0.02]$. The CON-DELAY group performed very similarly: $43.7 \%$ correct and $58.3 \%$ correct $[t(11)=2.92$, $P<0.02]$. There were no differences between the two groups (all $t \mathrm{~s}<1.1, P \mathrm{~s}>0.1$ ).

Recognition performance as a function of slide number is presented in Figure 2 for the CON, CONDELAY, and AMN groups. Overall, performance from slide to slide was roughly parallel across groups. A pronounced peak in recognition performance occurred for all three groups for slide 8 ,

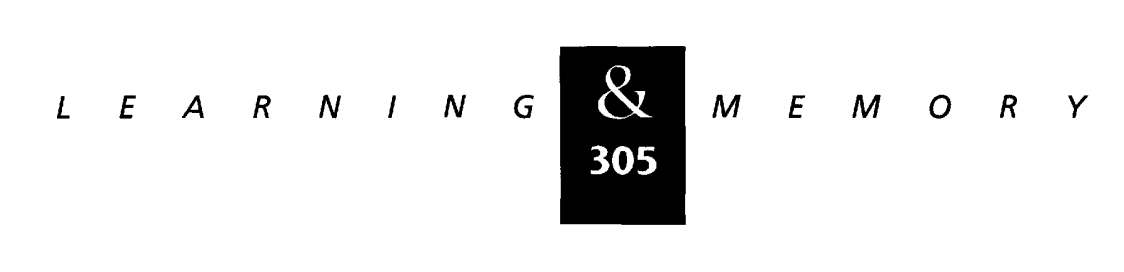




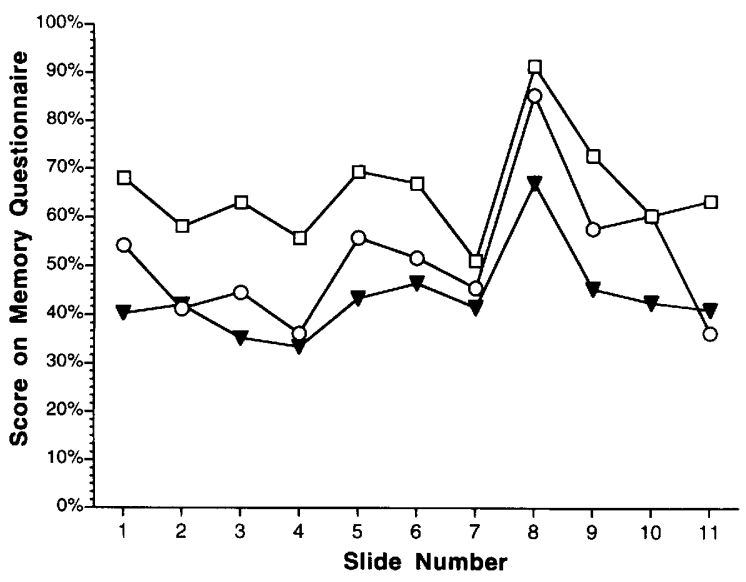

Figure 2: Recognition scores (percent correct) on the memory questionnaire as a function of slide number for the CON group (open square) $(n=9)$, the CON-DELAY group (open circle) ( $n=12$ ), and the AMN group (solid triangle) $(n=9)$. Slides $5-8$ and the accompanying narrative contained more emotional content than the other slides. S.E.M. ranged from 3.7 to 8.8 for the CON group, from 3.8 to 8.4 for the CON-DELAY group, and from 3.3 to 9.3 in the AMN group. Chance performance $=25 \%$.

which was part of the second, emotionally arousing phase of the story. This slide depicted a boy's reattached, severed legs. For all groups, recognition performance was higher for slide 8 than for any other slide. The magnitude of this peak was somewhat smaller for the AMN group compared with the CON and CON-DELAY groups. However, the subgroup of six amnesic patients, who closely matched the CON-DELAY group on memory performance in the first phase, showed a peak very similar to that of the CON-DELAY group [for AMN $n=6$ ), $53.6 \%$ on slide 8 ; for CON-DELAY, $58.3 \%$ ]. With one exception, every subject in the CON, CON-DELAY, and AMN groups had better memory for slide 8 than for the preceding, less arousing slide (slide 7, which showed surgeons in an operating room). The one exception was amnesic patient N.F., who scored rather well on the test items that pertained to both slides (slide 7, 71\% correct; slide $8,67 \%$ correct).

\section{Discussion}

There were four main findings: First, emotional arousal enhanced the declarative memory of both amnesic patients and control subjects. All three groups (AMN, CON, and CON-DELAY) exhib- ited improved recognition memory for material presented in the emotionally arousing, second phase of the story compared with the initial, emotionally neutral phase of the story. Second, as expected, the amnesic patients exhibited impaired recognition memory for all phases of the story when compared with subjects in the CON group, who were tested using the same short study-to-test delay $(2 \mathrm{~min})$ and experimental procedures. Yet, despite their overall impairment in declarative memory, the amnesic patients exhibited improved declarative memory for the emotionally arousing phase of the story, just as the CON group did. The AMN group was also measured against a CON-DELAY group, whose performance level had been approximately matched to the performance of the amnesic patients by testing after a long delay ( 1 week). This comparison indicated that the enhanced memory exhibited by the AMN group was proportional to the enhancement exhibited by normal subjects. In addition, when the two groups (AMN and CON-DELAY) were even more closely equated on memory performance for the first phase of the story by excluding three patients who scored close to chance, the magnitude of the emotional enhancement effect in both patients and control subjects were closely matched. Third, the findings from the phase-to-phase analysis of the story were supported by a slide-by-slide analysis. Recognition performance curves were roughly parallel for all groups, and all groups demonstrated the best recognition memory for slide 8 (severed legs). The pattern of slide-by-slide results is consistent with the results of other studies that used closely similar versions of this emotional story (Cahill et al. 1995; Adolphs et al., this issue). Fourth, the ratings of emotionality of the story by amnesic patients and control subjects were similar, consistent with recent studies of emotional responses in amnesic patients (Douglas and Wilkenson 1993; Hamann et al. 1997).

The proportional enhancement of memory for emotional stimuli in the amnesic patients and control subjects in the current study is consistent with the results of another recent study of amnesic patients that examined emotional reactions and memory following presentation of emotionally arousing pictures (Hamann et al. 1997). In that study, subjects viewed $\mathbf{4 0}$ pictures from the International Affective Picture System (IAPS; Lang et al. 1988) and rated each picture according to its emotional intensity (arousal) and pleasantness (valence). Emotional arousal (regardless of valence)

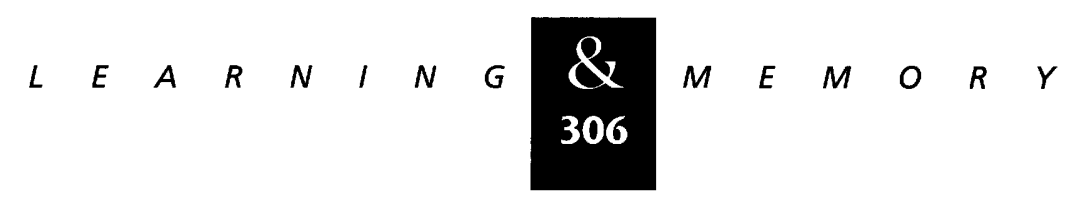


enhanced free recall and recognition for the pictures to the same degree in both amnesic patients and control subjects. Furthermore, ratings of arousal and valence were highly similar for amnesic patients and control subjects.

The finding that emotional arousal enhanced memory in the amnesic patients to the same degree as in the control subjects suggests a potentially useful strategy for memory rehabilitation. Specifically, our findings indicate that memory can be significantly enhanced in memory-impaired individuals if the to-be-remembered material elicits emotional arousal. Although the emotional arousal in the current study was negative in nature, both positive and negative emotional arousal have similar memory-enhancing effects (Hamann et al. 1997).

Earlier clinical reports suggested that patients with Korsakoff's syndrome are frequently abnormal in their emotional responses (Rapaport 1961; Talland 1965). However, in the current study the four patients with Korsakoff's syndrome were very similar to the other amnesic patients in their emotional ratings (mean rating $=7.5 \pm 1.0$ vs. $7.6 \pm 1.0$, for the Korsakoff and non-Korsakoff patients) and also similar in terms of the memory enhancement effect for emotional material (no group differences or interactions in recognition performance). Alcoholic Korsakoff's syndrome is variable with respect to the severity of memory impairment, frontal lobe signs, and other neuropsychological signs of cortical dysfunction. Our patients were selected on the basis of having a memory impairment disproportionate to other neuropsychological impairment. The emotional abnormalities described in earlier reports might occur in patients with a broader spectrum of neuropsychological deficits than would occur in patients with Korsakoff's syndrome selected especially for studies of memory. Notably, Douglas and Wilkenson (1993), who used similar selection criteria to those in the current study, also found intact emotional responsiveness to emotionally arousing stimuli in patients with Korsakoff's syndrome.

The findings for amnesic patients contrast sharply with the results obtained for two patients with bilateral amygdala lessions (Cahill et al. 1995; Adolphs et al., this issue). These patients did not exhibit enhanced memory for the emotionally arousing elements of the story, despite having normal memory for the first phase of the story. These results suggest that bilateral amygdala lesions impair or abolish the enhancement of declarative memory that is ordinarily produced by emotional stimuli.

Considerable evidence from studies with experimental animals suggests that the amygdala modulates memory by influencing memory storage processes occurring in other brain regions, such as the hippocampus (McGaugh et al. 1996). For example, stimulation of the amygdala influences memory in learning situations thought to require the hippocampus (Packard et al. 1994). Also, electrophysiological evidence demonstrates a modulatory influence from the basolateral amygdala on long-term potentiation (LTP) in the hippocampus (Ikegaya et al. 1994, 1995a,b,c, 1996). It is also possible that the amygdala modulates memory processes in the neocortex either directly, via its anatomical connections to secondary sensory regions (Iwai et al. 1987), or indirectly, via activation of diffusely projecting nuclei such as the nucleus basalis (Weinberger et al. 1990). The present findings do not allow us to distinguish between these possibilities.

Interestingly, neither bilateral amygdala lesions nor the medial temporal lobe or midline diencephalic lesions that produce amnesia affect the ability to assess the degree of emotional intensity (arousal) or pleasantness (valence) elicited by emotional stimuli. For example, two postencephalitic amnesic patients with large medial temporal lobe lesions that included the amygdala bilaterally, E.P. and G.T. (Hamann et al. 1997), gave arousal and valence ratings very similar to control subjects for a wide range of emotional stimuli. Similarly, the amnesic patients in the current study and the two patients with selective bilateral amygdala lesions in Adolphs et al. (this issue) gave ratings of their emotional reactions to the emotional story that were very close to those of control subjects. One possibility is that lesions to these structures do not affect emotional reactions. Alternatively, the rating of emotional material may not require the actual experiencing of the emotions normally elicited by the stimuli. Perhaps such ratings can be made strategically, on the basis of semantic knowledge.

In conclusion, damane to medial temporal lobe or midline diencephalic structures in the absence of amygdala damage results in amnesia but does not interfere with the effect of emotional arousal on the declarative memory that remains. Conversely, bilateral amygdala damage in the absence of damage to medial temporal lobe or midline diencephalic structures impairs the enhancement of declarative memory by emotional arousal

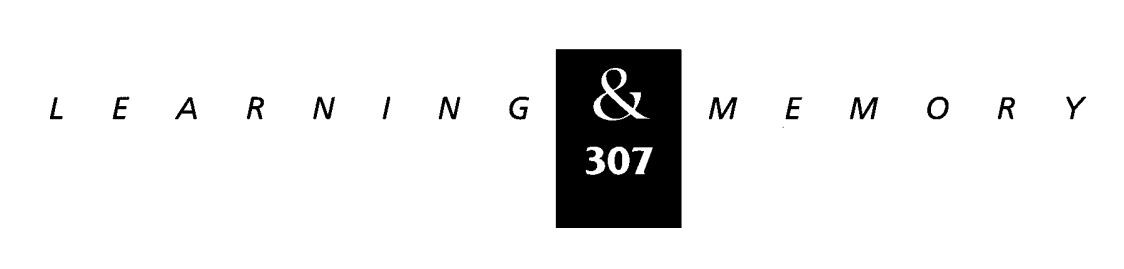


but does not affect declarative memory for emotionally neutral material (Adolphs et al., this issue). Neither lesion affects subjective ratings of emotional reactions to emotional stimuli. These findings suggest that the brain structures mediating the effect of emotional arousal on memory (e.g., the amygdala) exert their influence by modulating declarative memory (McGaugh 1993).

\section{Acknowledgments}

This work was supported by National Institute of Mental Health grant $\mathrm{MH} 24600$ and a McDonnell-Pew postdoctoral fellowship to S.H. Stephan Hamann is now at the Department of Psychology, Emory University. We thank Nicole Champagne, Brent Kronenberg, James Moore, Paul Murphy, and Joyce Zouzounis for research assistance. The publication costs of this article were defrayed in part by payment of page charges. This article must therefore be hereby marked "advertisement" in accordance with 18 USC section 1734 solely to indicate this fact.

\section{References}

Adolphs, R., L. Cahill, R. Schul, and R. Babinsky. 1997. Impaired declarative memory for emotional material following bilateral amygdala damage in humans. Learn. \& Mem. (this issue).

Cahill, L. and J.L. McGaugh. 1995. A novel demonstration of enhanced memory associated with emotional arousal. Consciousness Cognit. 4: 410-421.

Cahill, L., B. Prins, M. Weber, and J.L. McGaugh. 1994. Beta-adrenergic activation and memory for emotional events. Nature 371: 702-704.

Cahill, L., R. Babinsky, H.J. Markowitsch, and J.L. McGaugh. 1995. The amygdala and emotional memory. Nature 377: 295-296.

Davidoff, D.A., N. Butters, L.J. Gerstman, E. Zurif, I.H. Paul, and S. Mattis. 1984. Affective/motivational factors in the recall of prose passages by alcoholic Korsakoff patients. Alcohol 1: 63-69.

Davis, M. 1994. The role of the amygdala in emotional learning. Int. Rev. Neurobiol. 36: 225-266.

Douglas, J.J. and D.A. Wilkenson. 1993. Evidence of normal emotional responsiveness in alcoholic Korsakoff's syndrome in the presence of profound memory impairment. Addiction 88: $1637-1645$.

Gilbert, J., R. Levee, and K. Catalano. 1968. A preliminary report on a new memory scale. Percep. Motor Skills 27: $277-278$.

Granholm, E., J. Wolfe, and N. Butters. 1985.

Affective-arousal factors in the recall of thematic stories by amnesic and demented patients. Dev. Neuropsychol. 1: 317-333.

Hamann, S.B., L. Cahill, and L.R. Squire. 1997. Emotional perception and memory in amnesia. Neuropsychology 11: 104-113.

Heuer, F. and D. Reisberg. 1990. Vivid memories of emotional events: The accuracy of remembered minutiae. Mem. Cognit. 18: 496-506.

Ikegaya, Y., H. Saito, and K. Abe. 1994. Attenuated hippocampal long-term potentiation in basolateral amygdala-lesioned rats. Brain Res. 656: 157-164.

Ikegaya, Y., K. Abe, H. Saito, and N. Nishiyama. 1995a. Medial amygdala enhances synaptic transmission and synaptic plasticity in the dentate gyrus of rats in vivo. J. Neurophysiol. 74:(5) 2201-2203.

Ikegaya, Y., H. Saito, and K. Abe. 1995b. High-frequency stimulation of the basolateral amygdala facilitates the induction of long-term potentiation in the dentate gyrus in vivo. Neurosci. Res. 22:(2) 203-207.

1995. Requirement of basolateral amygdala neuron activity for the induction of long-term potentiation in the dentate gyrus in vivo. Brain Res. 671:(2) 351-354.

Ikegaya, Y., H. Saito, and K. Abe. 1996. The basomedial and basolateral amygdaloid nuclei contribute to the induction of long-term potentiation in the dentate gyrus in vivo. Eur. J. Neurosci. 8:(9) 1833-1839.

Iwai, E., M. Yukie, H. Suyama, and S. Shirakawa. 1987. Amygdalar connections with middle and inferior temporal gyri of the monkey. Neurosci. Lett. 83:(1-2) 25-29.

Kaplan, E.F., H. Goodglass, and S. Weintraub. 1983. The Boston naming test. Lea and Febiger, Philadelphia, PA.

Kritchevsky, M., L.R. Squire, and J.A. Zouzounis. 1988. Transient global amnesia: Characterization of anterograde and retrograde amnesia. Neurology 38: 213-219.

Lang, P.J., A. Ohman, and D. Vaitl. 1988. The International Affective Picture System. Center for Research in Psychophysiology, University of Florida, Gainesville, FL.

Markowitsch, H., J. Kessler, C. Bast-Kessler, and R. Riess. 1984. Different emotional tones significantly affect recognition performance in patients with Korsakoff psychosis. Internatl. J. Neurosci. 25: 145-159.

Markowitsch, H., J. Kessler, and P. Denzler. 1986. Recognition memory and psychophysiological responses to stimuli with neutral or emotional content: A study of Korsakoff patients and recently detoxified and longterm abstinent alcoholics. Internatl. J. Neurosci. 29: 1-35.

Mattis, S. 1976. Dementia Rating Scale. In Geriatric psychiatry (ed. R. Bellack and B. Keraso), pp. 77-121. Grune \& Stratton, New York, NY.

McGaugh, J.L., I.B. Introini-Collison, L.F. Cahill, C. 
Castellano, C. Dalmaz, M.B. Parent, and C.L. Williams. 1993. Neuromodulatory systems and brain storage: Role of the amygdala. Behav. Brain Res. 58: 81-90.

McGaugh, J.L., L. Cahill, and B. Roozendaal. 1996. Involvement of the amygdala in memory storage: Interaction with other brain systems. Proc. Natl. Acad. Sci.

93:(24) 13508-13514.

Oscar-Berman, M., M. Hancock, M.S. Mildworf, N. Hutner, and D.A. Weber. 1990. Emotional perception and memory in alcoholism and aging. Alcohol. Clin. Exp. Res. 14: 383-393.

Packard, M.G., L. Cahill, and J.L. McGaugh. 1994. Amygdala modulation of hippocampal-dependent and caudate nucleus-dependent memory processes. Proc. Natl. Acad. Sci. $91:(18) 8477-8481$.

Rapaport, D. 1961. Emotions and memory. Science Editions, New York, NY.

Rey, A. 1964. L'examen clinique psychologie. Presses Universitaires de France, Paris, France.

Squire, L.R. and A.P. Shimamura. 1986. Characterizing amnesic patients for neurobehavioral study. Behav. Neurosci. 100: 866-877.

Squire, L.R. and S. Zola-Morgan. 1991. The medial temporal lobe memory system. Science 253: 1380-1386.

Squire, L.R., D.G. Amaral, S. Zola-Morgan, M. Kritchevsky, and G.A. Press. 1989. Description of brain injury in the amnesic patient N.A. based on magnetic resonance imaging. Exp. Neurol. 105: 23-25.

Squire, L.R., D.G. Amaral, and G.A. Press. 1990. Magnetic resonance measurements of hippocampal formation and mammilary nuclei distinguish medial temporal lobe and diencephalic amnesia. J. Neurosci. 8: 4400-4410.

Talland, G.A. 1965. Deranged memory. Academic Press, San Diego, CA.

Teuber, H.L., B. Milner, and H.G. Vaughan. 1968. Persistent anterograde amnesia after stab wound of the basal brain. Neuropsychologia 6: 267-282.

Warrington, E.K. 1984. Recognition memory test. FER-Nelson, Windsor, UK.

Wechsler, D. 1981. Wechsler Adult Intelligence Scale-Revised. Psychological Corporation, New York, NY.

Weinberger, N.M., J.H. Ashe, R. Metherate, T. McKenna, D.M. Diamond, and J. Bakin. 1990. Retuning auditory cortex by learning: A preliminary model of receptive field plasticity. Concepts Neurosci. 1:(1) 91-132.

Received June 30, 1997; accepted in revised form September 23, 1997. 


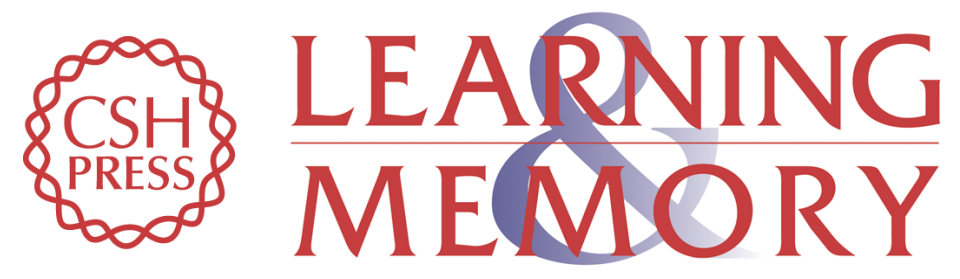

\section{Intact enhancement of declarative memory for emotional material in amnesia.}

S B Hamann, L Cahill, J L McGaugh, et al.

Learn. Mem. 1997, 4:

Access the most recent version at doi:10.1101//m.4.3.301

References This article cites 29 articles, 4 of which can be accessed free at: http://learnmem.cshlp.org/content/4/3/301.full.html\#ref-list-1

License

Email Alerting Receive free email alerts when new articles cite this article - sign up in the box at the Service top right corner of the article or click here. 